\title{
Financing Mode of Nature Reserve in China
}

\author{
Hu Xue Ping, Zhang Sheng Yong \\ College of Economics and Management, Huazhong Agricultural University, Wuhan, China
}

\section{Email address:}

393144887@qq.com (Hu Xue Ping), 393144887@qq.com (Zhang Sheng Yong)

\section{To cite this article:}

Hu Xue Ping, Zhang Sheng Yong. Financing mode of Nature Reserve in China. Science Discovery. Vol. 6, No. 1, 2018 , pp. 6-11. doi: $10.11648 /$ j.sd.20180601.12

Received: January 22, 2018; Accepted: February 26, 2018; Published: March 9, 2018

\begin{abstract}
As the deterioration of the external environment, insufficient capital investment and other perplexing problems on the management process, Chinese Natual reserve is faced with many threats, so the construction and protection of the Wetland Nature Reserve has become the urgent work of relevant departments. The primary task of building a conservation area to solve the problem of insufficient funds for the construction of protected areas. This paper mainly takes Hubei province Long gan Lake Natural Reserve as an example to analyze the nature reserve of existing financing mechanisms. On the basis of comparison and analysis, finally, the following conclusion is obtained: Longgan Lake Nature Reserve of Hubei province should try the financing model of PPP to cope with the shortage of construction funds.
\end{abstract}

Keywords: Longgan Lake, Nature Reserve, Wetland Protection, Funding Mechanism, Financing Model

\section{中国自然保护区融资模式分析}

\author{
胡雪萍, 章胜勇 \\ 经济管理学院, 华中农业大学, 武汉, 中国

\section{邮箱} \\ 393144887@qq.com（胡雪萍）,393144887@qq.com（章胜勇）
}

摘要: 由于外部环境恶化, 管理资金投入不足以及管理过程中存在错综复杂的问题, 中国自然保护区面临着许多威胁, 因此自然保护区建设已经成为刻不容缓的工作。而建设保护区的首要任务解决保护区建设资金需求不足的问题。本文 主要以中国湖北省龙感湖自然保护区为例分析了该自然保护区现有资金机制，然后对比不同融资模式的特点，并深入 探索适应龙感湖自然保护区的融资模式, 最后得到如下结论：PPP的融资模式引入到龙感湖自然保护建设管理中将促 进政企合作，实现双赢。

关键词: 龙感湖, 自然保护区, 湿地保护, 资金机制, 融资模式

\section{1. 引言}

中国湿地具有分布范围广、生物具有多样性、区域之 间差异性大的特点。20世纪90年代中期, 开展了全国湿地 资源调查，时间长达6年。2004年2月经国务院批准，中国 国家林业局公布了《全国湿地保护工程规划》 [1]。中国对 湿地保护高度的关注和重视, 但中国作为一个发展中国家,
总体而言仍然处于资金匮乏的格局, 没有充足的资金投入 到保护建设工作中去。

龙感湖自然保护区作为国家重点自然保护区之一具 有很好的代表性。它存在着投资总量不足、建设资金无法 满足资金需求、投资水平也稂莠不齐的问题。本文将以湖 北省龙感湖自然保护区为例来具体探讨中国自然保护区 
资金机制方面存在的问题，分析寻求适合自身发展的融资 模式并提出了一系列可行性政策。

\section{2. 龙感湖自然保护区概况}

龙感湖自然保护区地处湖北省黄冈县境内, 2009年被 批准为中国国家级自然保护区。保护区容纳了差异性的生 态系统类别, 同时气候温和、光照适宜, 是候鸟越冬迁徙 的中转站和珍稀野生动植物的栖息地, 具有非常珍贵的生 态、科研以及经济价值。

\section{3. 龙感湖自然保护区资金需求投入及问题分析}

\section{1. 龙感湖自然保护区资金需}

表1 保护区资金需求。

\begin{tabular}{ll}
\hline 资金需求 & 主要内容 \\
\hline 转变资源利用方式的成本 & 网箱拆费用 \\
& 渔民安置费用及其它对资源利用受限主体的补偿费用 \\
恢复湿地成本 & 湿地恢复工程费用 \\
& 湿地有害生物防治费用 \\
建设绿化带成本 & 改善保护区土壤、水质工程费用 \\
恢复栖息地成本 & 污染清理费用 \\
监督管理活动成本 & 野生动物栖息地恢复工程费用 \\
& 人员工资、日常办公费用 \\
& 能力建设 \\
保护管理活动成本 & 基础设施建设、设备购置 \\
& 巡护、管护 \\
& 检测、评估、科研、宣教、救护 \\
\hline
\end{tabular}

龙感湖自然保护区未来的工作重点主要概括为三大 块, 分别为完善基础设施的建设、珍稀动物以及动物栖息 地的恢复，对保护区存在的明显问题按照林业局和政府要 求进行整改。根据实际调查总结出来的龙感湖自然保护区 的所有资金需求如表1所示, 其中最急需的资金有湿地恢 复工程资金、建设绿化带资金、保护区能力建设资金、基 础设施建设资金以及科研水平提升资金, 其次是网箱拆除 资金、渔民安置资金、栖息地恢复资金和清理污染资金, 最后就是人员经费和有害生物防治等资金需求。经保护区 专业人员计量测算出了龙感湖自然保护区主要工程项目 费用, 其中保护与恢复工程 5127.90 万元, 占 $58.22 \%$; 科研 检测工程 1019.93 万元, 占 $11.58 \%$; 宣传教育工程 246 万元,
龙感湖国家级自然保护区业务上由黄冈市林业局来领 导, 行政隶属于黄梅县(中国湖北省)人民政府, 保护区使用 的是两极管理体系, 即保护区管理局和保护管理站。目前, 保护区从事科研工作人员较少, 仅能满足基础技术性工作的 需要, 要进一步深入进行研发, 还需要加强相关科研人才的 引进。保护区自成立以来克服难题, 积极发展建设, 目前主 要建成了动植物标本馆和科研中心, 还配置了部分办公以及 科研设备, 为后续保护发展工作奠定了一定的基础。

表2 龙感湖自然保护区中国林业部门投资一览。

\begin{tabular}{|c|c|c|c|c|c|c|c|c|c|c|}
\hline \multirow[b]{2}{*}{ 序号 } & \multirow[b]{2}{*}{ 名称 } & 投入形式 & 资金来源 & \multicolumn{7}{|c|}{ 金额（万元） } \\
\hline & & $\begin{array}{l}\text { 1常规预算 } \\
\text { 2项目申请 }\end{array}$ & $\begin{array}{l}\text { 2省财 } \\
\text { 3市财 } \\
\text { 4县财 }\end{array}$ & 2016 & 2015 & 2014 & 2013 & 2012 & 2011 & 合计 \\
\hline 一 & 人员经费 & 1 & 2,4 & 258.9 & 196.98 & 166 & 143.8 & 150 & 99 & 1014.68 \\
\hline 二 & 项目经费 & 1,2 & 1,2 & $\begin{array}{l}1013 \\
1271.90\end{array}$ & $\begin{array}{l}2427 \\
2623.98\end{array}$ & $\begin{array}{l}7 \\
173\end{array}$ & $\begin{array}{l}117 \\
260.8\end{array}$ & $\begin{array}{l}1402 \\
1552\end{array}$ & $\begin{array}{l}14 \\
99\end{array}$ & $\begin{array}{l}4980 \\
5994.68\end{array}$ \\
\hline
\end{tabular}

龙感湖自然保护区主要资金来源于湖北省林业局以 及政府拨付的专项经费和事业经费, 这些资金主要用于支 付职工工资、日常办公、部门巡护经费以及项目开展经费 等。专项资金，基建项目投入很少，因此保护区在科研、 基础设施建设以及入职员工培训等方面的各种不能开展。
占 $2.79 \%$; 站点标识牌建设 488.88 万元, 占 $5.55 \%$ 。虽然目 前政府对保护区有了一部分资金投入但投入的资金远远 不足，制约着保护区的可持续发展。龙感湖自然保护区的 资金缺口, 根本上来自对自然保护区的保护和恢复缺口, 也就是提升保护管理水平所需的资金和湿地恢复的资金。

\section{2. 龙感湖自然保护区资金投资}

在对龙感湖自然保护区、湖北省林业厅、财政厅农财 处进行走访座谈、实地调研的基础上, 广泛收集近年来相 关资料, 并进行归纳整理, 梳理其资金投入现状。龙感湖 自然保护区国内林业部门投资如表2所示。
在所有的资金投入中，人员经费有上升的趋势，由于龙感 湖自然保护区属于公益类事业单位, 没有公用经费拨款, 临时人员工资只能通过项目资金来支付。此外由上表还了 解到项目资金拨付情况来看, 波动幅度较大, 保护区的项 目资金主要来源于自然保护区与湿地项目及部分中央财 
政和省级财政的专项资金，但此部分资金并不稳定。主要 是由于中国宏观政策发生了变化, 主要的项目资金来源于

湿地保护补贴、基数设施建设资金。

表3 国际投入资金表。

\begin{tabular}{llllllll}
\hline 序号 & 机构名称 & 性质 & 项目名称 & $\mathbf{2 0 1 6}$ & $\mathbf{2 0 1 5}$ & 资金（万元） & 内容 \\
\hline 1 & GEF & 1 & 加强湖北湿地保护, 保护实务多样性 & 9 & 27.61 & 36.61 & 候鸟保护 \\
\hline
\end{tabular}

国际投入资金情况如表3所示。国际投入性质主要包 括国际多边组织; 国际双边援助; 国际企业和个人捐赠。 龙感湖自然保护区于2015和2016年分别收到了联合国开 发计划署的资金投入，联合国开发计划署是世界上最大的 负责进行技术援助的多边机构。它是联合国的一个下属机 构, 总部位于纽约。联合国开发计划署的工作是帮助不发 达国家, 并为支持发展中国家提供培训人才和为之提供设 备以及给予他们技术层面的建议。致力于推动可持续发展。 不过，国际资金的投入时常以实物、项目的形式进入，客 观上提高自然保护区的管理水平。

龙感湖自然保护区享有独特的先天优势, 它是中国保 持最为完好的重要淡水湖泊湿地之一。而至今以来保护区 自养能力较为欠缺, 不能达到财务自主。目前自营收入主 要体现在养殖业和对利用湖面资源的渔民征收资源使用 费, 但这一部分经营全部由社区负责, 收入仅仅能满足发 展社区建设的需要。

\section{3. 龙感湖自然保护区存在的主要问题}

根据对龙感湖自然保护区资金需求投资的具体分析, 发现了龙感湖保护区主要存在以下问题: 保护区资金来源 渠道单一, 主要依赖于中央和省市县的财政拨款; 保护区 内部融资能力不足, 自身资源没有得到合理利用, 也没有 通过金融市场的手段采取合理融资模式达到自营创收的

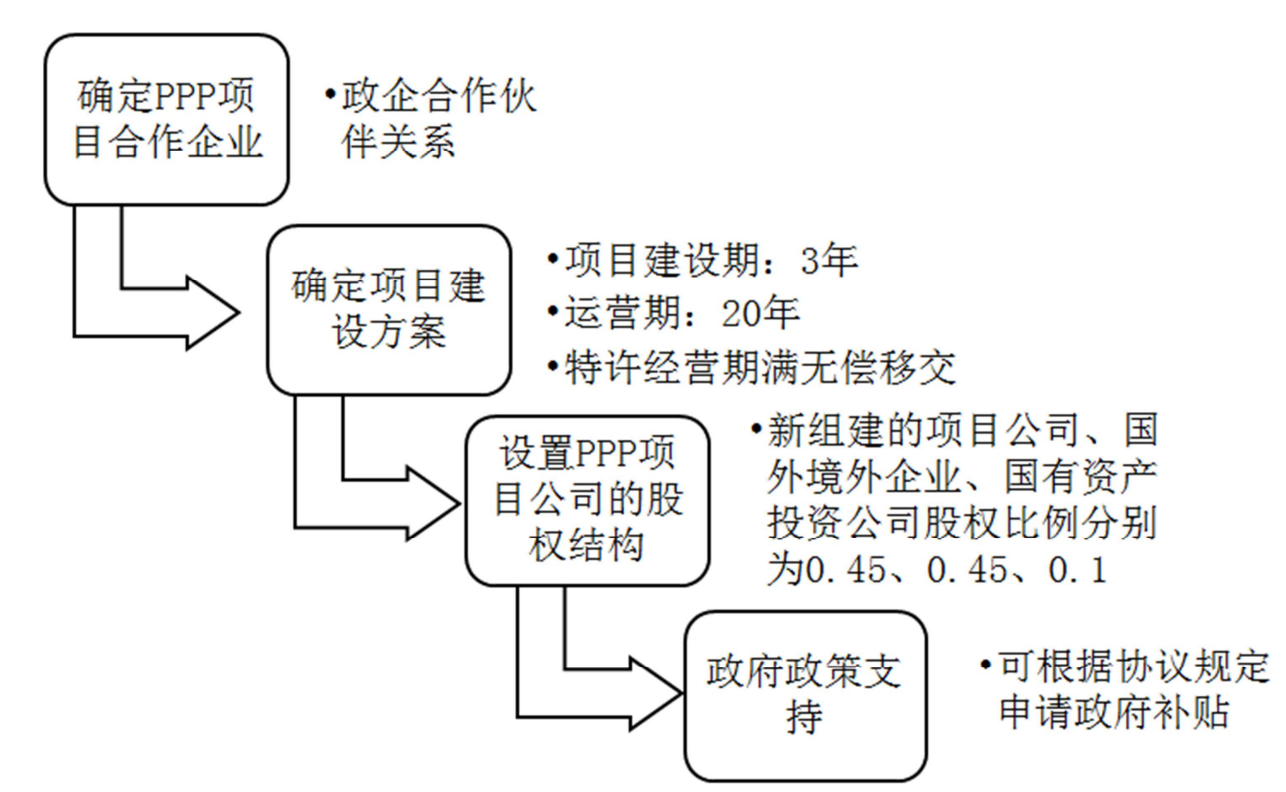

图1 PPP的运作模式。
目的; 保护区资金缺口大，主要表现为治理保护经费、基 础设施建设资金、科研经费等的匮乏。

\section{4. 龙感湖自然保护区融资模式的探索}

基于上文分析了解到中国自然保护区为完善保护区 建设管理的大量资金需求与资金投入不足之间的矛盾, 我 们要解决这一问题除了需要依托于中国政策性投资、国际 援助以及多边机构捐赠等多种融资渠道, 更要借助金融、 市场、贸易等手段探索适宜的融资模式。过去多年，自然 保护区融资模式比较单一, 由政府单独投资, 由于行政体 制、制度等原因, 以及政府部门缺乏竞争动力和追求利润 最大化的愿望，因此自然保护区普遍管理效率低下，面临 资金贵乏的问题，同时对于整个社会来说也带来了整体福 利下降和资源配置不合理的问题。因此，下面分析比较几 种具有典型性的项目融资模式在自然保护区融资过程中 的运用, 并阐述这些案例对龙感湖自然保护区发展的启示。

\subsection{PPP模式}

PPP通常是政府部门与企业各自发挥优势, 共同经营, 风险共担, 利益共享, 提高公共产品和服务的供给质量和 效率, 获得比单独行动更有利结果的经营模式。该模式能 有效降低政府债务风险, 缓解政府资金短缺的问题 [2]。中 国沿海红树林和湿地自然保护区就是采用PPP运作模式。
PPP模式运用在红树林和湿地保护区的建设过程中大 大增加了项目融资, 解决了政府财务负担和投资压力, 同
时也提升了保护区管理效率, 给整个社会带来了双赢的效 应[3]。 


\subsection{BOT模式}

BOT项目融资模式是政府授予一定期限的特许专营 权给私营企业, 让其参加基础设施投资、建设和经营的一 种方式。被授权企业在协议规定时间内筹集资金建设和经 营特定的公用基础设施, 并向使用者收取费用或者销售产 品来获取收入, 以此清偿贷款并赚取利润。同时政府对授 权企业提供的公共产品和服务的数量和价格加以限制, 以
保证私人企业能够获取利润。特许权期满时, 该基础设施 按照约定无偿或以很少的名义价格移交给政府部门[4]。

南京秦淮河湿地公园是社会公益性地城市绿色基础 设施建设项目, 它的主要目标是为全社会提高公共产品服 务, 不宜采取商业性项目的融资方式, 同时也比较符合 BOT融资模式的特点, 因此该项目采取了BOT模式来筹集 资金。BOT的运行模式如图3所示。

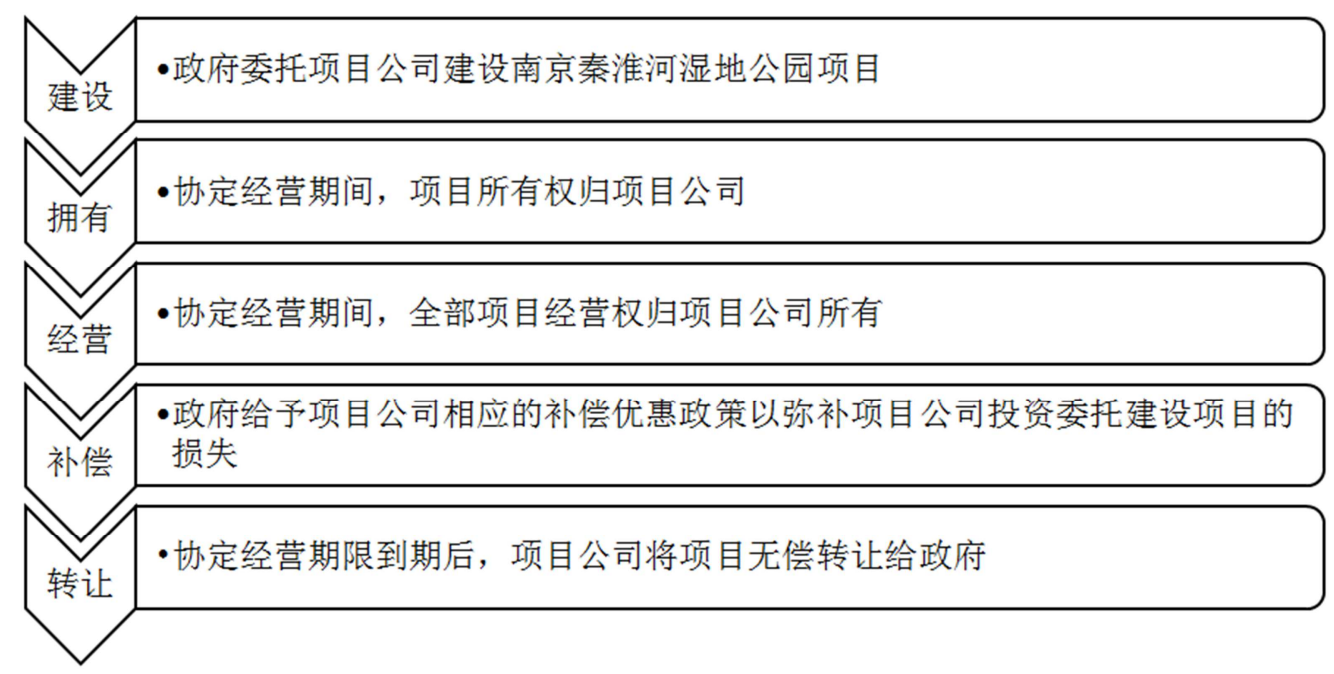

图2 BOT的运作模式。

南京秦淮河湿地公园属于典型的社会公益建设项目, 项目建设所需资金量大, 利用BOT模式解决了建设资金不 足和建设管理效率低的问题, 同时这个案例也体现了BOT 模式建设资本适当盈利和公益性项目建设经营顺利的原 则。

\subsection{RCP模式}

$\mathrm{RCP}$ 是一种资源补偿项目模式, 这种方式中政府部门 对湿地项目享有部分控制权, 运作程序首先是选定实施
$\mathrm{RCP}$ 融资的基础设施项目, 并完善立项手续, 并确定资源 补偿方式, 然后发布招商广告, 并与潜在的投资者进行商 谈, 择优签订合同, 最后由投资者按照合同实施项目建设。

深圳市 (中国) 政府初步规划想要投资 8 亿元打造总 规模约 400 公顷的湿地公园, 但由于财政紧张无力负担银 行高额利息, 同时没有对湿地公园的到访者收费的计划, 为了该湿地公园融资困境, 政府部门使用了 $\mathrm{RCP}$ 的融资模 式，该融资模式的具体运作流程如图4所示 [5]。

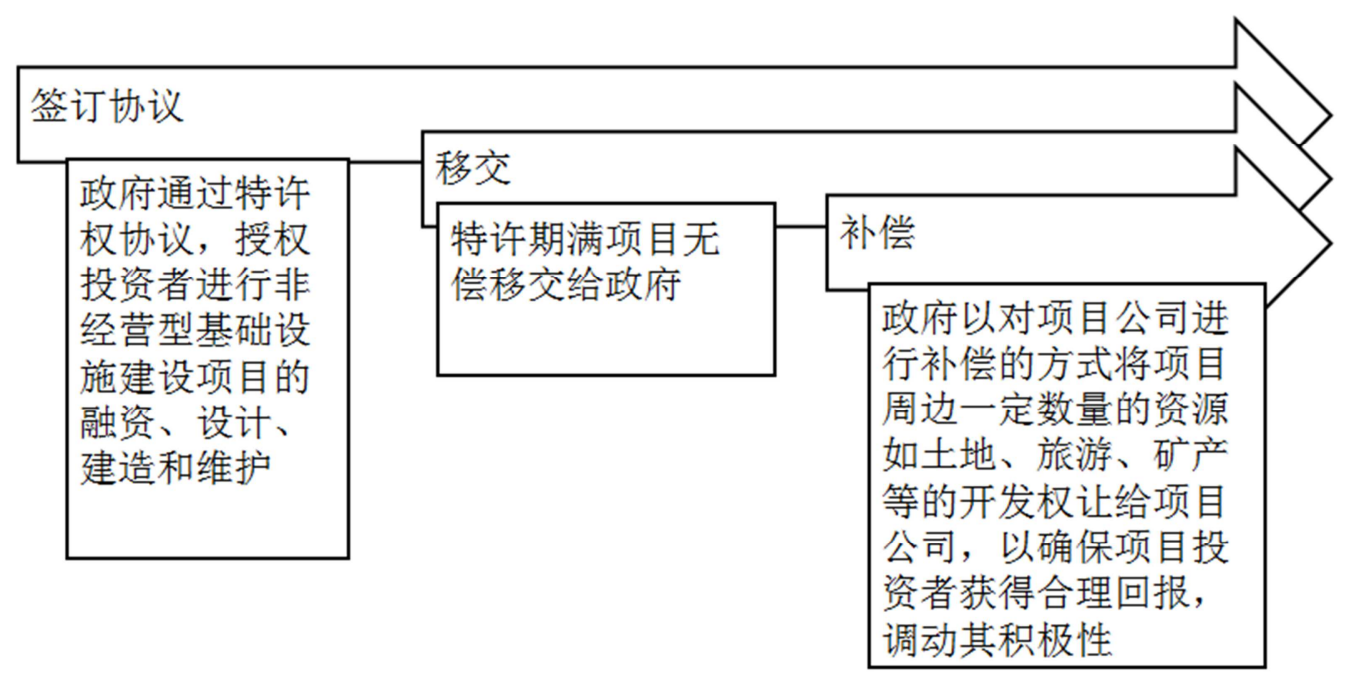

图3 RCP的运作模式。

上述项目属于典型的非经营性基础设施类公用事业 项目, 政府部门选择具有吸引力的四块住宅用地作为潜在
的补偿用地, 这片居住用地交通便利、周围环境优美, 因 此根据规划, 湿地公园建成以后价值必然会提升。通过这 
种方式, 政府不仅规避了项目融资产生的风险同时也减轻 了自己的工作量。

\section{4. 龙感湖自然保护区融资模式的适应性分析}

上文分析了BOT、PPP、RCP三种融资模式在自然保 护区和湿地公园建设领域的应用, 这三种融资模式有各自
不同的特点和适用范围，下面首先比较这三种不同的融资 模式, 然后结合龙感湖自然保护区自身的特点深入探索该 保护区适合的融资模式, 具体的项目融资模式对比分析如 表4所示。

表4 项目融资模式比较表。

\begin{tabular}{|c|c|c|c|}
\hline 项目融资模式类别 & BOT & PPP & RCP \\
\hline 项目所有权 & 拥有 & 部分拥有 & 拥有 \\
\hline 项目经营权 ～～～～～～ & 转交之前暂时失去 & 部分拥有 & 转交之前暂时失去 \\
\hline 短期获得资金的难易程度 & 难 & 较易 & 较难 \\
\hline 融资成本 ～～～～～～～～ & 最高 & 一般 & 较高 \\
\hline 担保 & 一般需要政府做最低收益担保 & 不需要政府提供最低收益担保 & 不需要政府提供最低收益担保 \\
\hline 风险分配 & 政府和投资者风险均大 & 政府和投资者风险一般 & 投资者承担了绝大部分风险 \\
\hline 融资需要时间 & 最长 & 较短 & 较长 \\
\hline 对宏观经济影响 & 利弊兼具 ～～～～～～～～～～等 & 有利 & 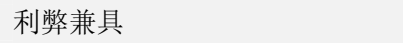 \\
\hline 适用范围 & 有长期稳定现金流的项目 & 准经营性项目 & 非经营性项目或者准经营性项目 \\
\hline
\end{tabular}

上表对这些融资方式的适应性进行了比较, 由此可知 BOT、PPP、RCP这三种融资模式均可应用于自然保护区 建设项目, 这些融资模式各有优缺点。我们应根据不同的 自然保护区自身差异性的特点来决定使用哪一种融资模 式。在许多发达国家，湿地公园、植物园、自然保护区等 的建设属于纯公益性的非经营性项目, 但在发展中国家, 这些本应列入非经营性的项目, 基于可持续发展的角度, 也被列入了准经营性项目。龙感湖自然保护区基础设施建 设项目一方面旨在保护和恢复湿地, 一方面也为湿地建设 提供资金支持以及为社区和当地发展带来经济效益，因此 也属于准经营性项目。该保护区资金投资不能满足基础设 施项目建设工作以及开展宣传、科研监测、巡护等保护区 能力建设方面的工作的需要。为解决难题, 龙感湖保护区 应当利用自身优势来引入私人资本来寻求保护区和周边 社区共同发展。龙感湖自然保护区具备竞争性的特征主要 体现在以下几个方面。

（1）保护区内有大源湖、自然湿地、珍稀动植物等 天然景观, 管理人员可以聘请专业策划人员着意打造风光 游和主题游会, 借此宣传保护区的绿色经营理念。同时可 以建设游客接待中心, 为游客提供休闲散心的舒适场所, 打造环保型旅游产业链, 使人们在亲近自然的过程中提升 环保意识, 并为保护区的可持续发展建设提供资金力量。

(2) 保护区邻近四祖禅寺, 同时黄冈 (中国湖北省) 地区的黄梅戏远近闻名, 因此可以开展以参观禅诗和欣赏 黄梅戏为主的地方风情游, 增进对黄梅及古老文化的了解。

（3）保护区以其原生态的湿地和生物将吸引着不少 高校、科研单位前来参观考察, 也可以成中小学生接受自 然、进行环境教育的理想场所, 通过组织夏、冬令营, 让 下一代接受保护生物多样性、爱护自然的教育, 成为保护 环境的自觉参与者。

龙感湖自然保护区建设项目顾政府、保护区管理局以 及私人企业多方利益, 以“多赢”为理念, 项目建设完成以 后可以凭借其资源优势获取可观的经济价值。以上条件均 是PPP融资模式的必要条件, PPP要求公共管理部门和民 营企业合作协调，达到“帕累托”最优的状态，整个社会达 到了效益最大化。相比BOT模式, PPP模式在龙感湖自然
保护区也更加具有优势, 首先BOT的参与方是等级式的, 各参与方存在利益冲突, 由于信息不对称, 一方参与者可 能会以牺牲另一方的利益为代价来达到自己的理想状态, 虽然博弯双方实现了“纳什均衡”但是对于整个社会来说 有一些无谓损失。而PPP融资模式避免了发生这样的情况, 更加符合公共设施建设的宗旨。另外, 在PPP融资模式中, 民营企业参与方从项目认证阶段就开始参与进来, 而 $\mathrm{BOT}$ 则是在项目招标阶段参与的, 这样PPP融资模式省去很多 前期由于不信任对项目进行考察所耗费的时间成本和物 质成本, 因此PPP模式融资成本更低, 融资风险也相对较 小，更易获得资金投入。另外 RCP融资模式也不适合运用 在龙感湖保护区的建设项目中, RCP要求使用资源补偿前 期私人资本成本和利润，一般适用于非经营性的项目，而 龙感湖自然保护区的主要目的是保护和合理利用自然资 源, 这与通过资源补偿方式收回投资的 $\mathrm{RCP}$ 融资模式在很 大程度上是背道而驰的。由此可见, 龙感湖保护区适宜于 采取PPP融资模式. 通过在龙感湖自然保护区实施PPP融资 模式，政企达成协议，由政府和私人机构对保护区合作参 与龙感湖保护区投资、建设和特许经营, 通过合理规划实 现龙感湖自然保护区以保护和发展湿地资源为中心的宗 旨; 同时也使龙感湖保护区在一定时期内筹到资金进行建 设并提供环保产品和服务, 发展生态旅游, 引导居民改变 传统生活方式。

\section{5. 完善PPP模式在我国自然保护区发展运用的对 策}

PPP融资模式在自然保护区项目建设的发展运用可操 作性强, 但项目运营周期较长、对参与方专业能力要求高, 政府、保护区公共管理部门以及民营企业在项目的各个环 节中都需要有团队精神, 因此前提出了几点建议。

\section{1. 转变职能}

在传统的自然保护区管理中，政府大多采用“一揽子” 政策, PPP项目引入了市场中的竞争机制, 要求政府及其 
指定公共管理部门严格履行契约, 政府及其指定公共管理 部门需要转变职能, 改革创新, 减少干预, 发挥政府和指 定管理部门监督指导的的作用, 留更多的空间给民营企业 参与方。

\section{2. 加强交流}

在自然保护区发展中, 政府及其指定公共管理部门追 求的目标是尽可能增加公共利益, 而民企则着眼于收回投 资成本和自身利润最大化，在预期收益达不到预期时，可 能会与公共管理部门意见出现分歧, 降低甚至破坏协约, 因此中国政府和自然保护区公共管理部门应当吸取全球 PPP项目实施经验, 努力促进各方参与者达成共识, 齐心 协力让自然保护区建设项目顺利实施。

\section{3. 健全体系}

自然保护区的PPP融资模式运作起来十分复杂，对参 与方技术要求高, 同时要求他们具备丰富的财务、管理、 经济、法律以及自然保护区生态环境等等方面的专业知识, 因此专业化的服务机构有助于项目的顺利进行。然而, 现 阶段, 我国中介服务体系尚不成熟, 因此需要提升中介服 务机构业务水平, 提高综合素质, 为PPP项目顺利开展给 予可靠的人才和技术支持。

\section{参考文献}

[1］世界湿地日[J].科技与生活,2012,5(3),12-13。
[2] 陈明,张剑智, 孙丹妮. 借鉴国际经验构建环保部门财政支 出绩效评价[J].环境保护,2013,11(7):15-16。

[3] 刘子刚. 促进湿地保护和恢复的经济手段 [J]. 生态 境.2015,17(13):36-37。

[4] PPP Model Opportunities, Limitations and Risks in Croatian Public Project Financing[J]. Diana Car-Pu. Procedia-Social and Behavioral Sciences. 2014.

[5] The analysis of BOT strategies based on game theory-case study on Taiwan's high speed railway project. Tien-Chien Chen, Yu-Cheng Lin, Lung-Chuang Wang. Journal of Civil Engineering and Management. 2012.

\section{作者简介}

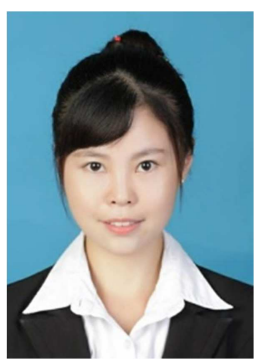

胡雪萍; 湖北仙桃人; 出生年月 : 1990 年3月; 华中农业大学经济管理学院在 读硕士; 研究方向: 农业经济、企业财 务管理。 